\title{
Humanização e reforma psiquiátrica: a radicalidade ética em defesa da vida $^{1}$
}

Humanization and psychiatric reform: a radical ethic in defense of life Humanización y psiquiátrica reforma: una ética radical en defensa de la vida

\section{Ana Rita Castro Trajano}

Universidade Federal de Minas Gerais, Belo Horizonte, MG, Brasil.

\section{Rosemeire Silva}

Conselho Federal de Psicologia, Belo Horizonte, MG, Brasil.

\section{Resumo}

Procurou-se discutir sobre interlocuções entre a Política Nacional de Humanização da Atenção e Gestão do Sistema Único de Saúde - PNH / SUS e a Reforma Psiquiátrica, em especial, a Política de Saúde Mental de Belo Horizonte, agraciada em 2004, pelo Ministério da Saúde, com o Prêmio HumanizaSUS Davi Capistrano Filho, quando destacou-se do conjunto dos trabalhos premiados por ser entre tantos - centenas de exitosas práticas de Humanização do SUS - aquela que inscrevia a experiência de desconstrução do manicômio no contexto da construção do SUS. Na abordagem dos 20 anos de história da Política de Saúde Mental de Belo Horizonte enfatizou-se o colorido próprio dado pela Saúde Mental à Política de Humanização, ou como esta é matizada no fazer da clínica antimanicomial. Procurou-se problematizar o cenário atual de elaboração de políticas públicas sobre drogas, propondo reflexões sobre loucura e drogadição como experiências eminentemente humanas.

Palavras-chave: Política de Humanização, Reforma Psiquiátrica, Política de Saúde Mental, Defesa da Vida, SUS.

\footnotetext{
Abstract

We attempted to discuss dialogues between the National Humanization Policy upon Care and Management of the Unique Health Sistem - SUS - and Psychiatric Reform, particularly the Mental Health Policy in Belo Horizonte, awarded with the Prize HumanizaSUS David Capistrano Filho in 2004 by the Ministry of Health, when it was featured from all the winning entries, being the only one which has inscribed the deconstruction asylum experience in the context of SUS construction among hundreds
} 
of others successful SUS Human Care practices. By the approaching of the 20 years of Belo Horizonte Mental Health Policy history, it was emphasized the singular Mental Health coloring given to the politics of Humanization, or even how it is nuanced in the deeds of anti-asylum clinic. We also attempted to discuss the current status of public policies development on drugs, offering reflections upon madness and drug addiction as eminently human experiences.

Keywords: Humanization Policy, Psychiatric Reform, Mental Health Policy, Defense of Life, SUS.

\section{Resumen}

Tratamos de discutir los diálogos entre la Política Nacional de Humanización de Atención y Gestión del Sistema Universal de Salud - SUS y de la Reforma Psiquiátrica, en particular, la Política de Salud Mental en Belo Horizonte, otorgado en 2004 por el Ministerio de Salud, Premio HumanizaSUS David Capistrano Filho, cuando se destacó entre todos los ganadores de estar entre tantos - cientos de exitosas prácticas de humanizacion del SUS - uno que inscribe la experiencia de deconstrucción del asilo en el contexto de la construcción del SUS. Al abordar la historia de 20 años de Políticas de Salud Mental de Belo Horizonte, fue destacado por el color propio dado por La Política de Salud Mental de Humanización, o como es matizada en la toma de antimanicomial clínica. Tratamos de analizar el estado actual de desarrollo de las políticas públicas en materia de drogas, ofreciendo reflexiones sobre la locura y la adicción a las drogas como experiencias eminentemente humanas.

Palabras clave: Política de Humanización, Reforma Psiquiátrica, Política de Salud Mental, Defensa de la Vida, SUS.

\section{Apresentação}

Política de Humanização e Reforma Psiquiátrica se encontram na radicalidade ética em defesa da vida. Experiências de cuidado em saúde mental na lógica da clínica antimanicomial nos dizem sobre a humanização do cuidado e da gestão do SUS ao derrubar muros, buscar a liberdade, a defesa dos direitos dos sujeitos com sofrimento psíquico ou mental, enfim, ao transformar relações e modos de existir, desestabilizando 
fronteiras de saberes, territórios de poder e modos instituídos de constituição de processos de trabalho em saúde.

Propomos a elaboração deste artigo por reconhecer e valorizar a Luta Antimanicomial e a Política de Saúde Mental de Belo Horizonte (Secretaria Municipal de Saúde de BH, 2008), desde os seus primeiros movimentos, na década de 90 do século passado. Em 2004, esta política conquistou o Prêmio HumanizaSUS Davi Capistrano Filho, pelo Ministério da Saúde, quando destacou-se por ser aquela que inscrevia a experiência de desconstrução do manicômio no contexto da construção do SUS.

Num primeiro momento, discutimos sobre o cenário de emergência da PNH e sua formulação como política pública transversal do SUS; a partir daí, abordamos os sentidos de humanização como conceito-experiência e os debates que se travaram entre os formuladores da política na época de sua elaboração. Considerando esses referenciais da PNH, abrimos conversa sobre a Política de Saúde Mental de Belo Horizonte e interlocuções possíveis entre Humanização e Reforma Psiquiátrica na construção de uma outra lógica na abordagem da loucura e do louco. Ao final, procuramos problematizar $\mathrm{O}$ cenário atual de elaboração de políticas públicas sobre drogas, propondo reflexões sobre loucura e drogadição como experiências eminentemente humanas.

Esperamos com esta produção conjunta contribuir para o fortalecimento dos laços entre a Política de Humanização e a Política de Saúde Mental, aprofundando os debates e reflexões sobre os desafios contemporâneos do SUS e os novos cenários que se apresentam com a implementação da Rede de Atenção Psicossocial (RAPS) e a elaboração de políticas públicas sobre drogas.

\section{Política Nacional de Humanização e a Luta Antimanicomial}

A Política Nacional de Humanização (PNH), também conhecida como HumanizaSUS, emergiu como política pública transversal de fortalecimento do SUS, em 2003, no bojo de processos de avaliação, que envolveram atores implicados com a construção de um 
sistema público de saúde universal $e$ igualitário.

Ressaltamos, nesse cenário de emergência e formulação da $\mathrm{PNH}$, como política pública de 'reencantamento do SUS', sua dimensão micro/molecular ${ }^{2}$ e sua aposta no 'método da tríplice inclusão', ao caminhar, conforme seu DocumentoBase (Ministério da Saúde, 2008), no sentido da inclusão, nos processos de produção de saúde, dos diferentes agentes implicados nestes processos, e que podemos sistematizar da seguinte forma: (i) inclusão dos diferentes sujeitos, produzindo autonomia, protagonismo e corresponsabilidade; (ii) inclusão do coletivo, seja como movimento social organizado, seja como experiência coletiva dos trabalhadores da saúde, tendo as Redes como referencial maior de constituição e fortalecimento dos Coletivos; (iii) inclusão dos analisadores sociais, ou seja, dos fenômenos que desestabilizam os modelos tradicionais de atenção e de gestão, acolhendo e potencializando os processos de mudança, ao favorecer a Análise Coletiva dos Conflitos.

Esses movimentos de formulação da PNH como política 'transversal e instituinte', não como um programa ou uma portaria/norma do SUS, produzem resultados que compõem um 'Documento-Base' (Ministério da Saúde, 2008), no qual é apresentada a estruturação da política a partir de seus três princípios, do 'método da tríplice inclusão' e de diretrizes, como orientações éticas, políticas e clínicas, deste novo modo de fazer e abordar a atenção e a gestão do SUS. Entende-se por princípio o que “causa ou força a ação, ou que dispara um determinado movimento no plano das políticas públicas" (Ministério da Saúde, 2008, p. 23). Neste sentido, a $\mathrm{PNH}$, como movimento de mudança dos modelos de atenção e gestão, possui três princípios a partir dos quais se desdobra enquanto política pública de saúde: (1) Indissociabilidade entre atenção e gestão: alteração dos modos de cuidar inseparável da alteração dos modos de gerir, inseparabilidade entre clínica e política, entre produção de saúde e produção de sujeitos; (2) Transversalidade: aumento do grau de comunicação intra e intergrupos transformação dos modos de relação e comunicação entre os sujeitos, desestabilizando fronteiras dos saberes, territórios de poder e modos instituídos de gestão do processo de trabalho; (3) 
Protagonismo, corresponsabilidade e autonomia dos sujeitos e coletivos.

Vale ressaltar que as diretrizes, no caso da PNH, expressam o 'método da tríplice inclusão’ e apontam no sentido da: Clínica Ampliada; Cogestão; Valorização do Trabalho e da Saúde dos Trabalhadores; Acolhimento; Defesa dos Direitos dos Usuários; Ambiência; Fomento das grupalidades, coletivos e redes; Construção da Memória do SUS que dá certo (Ministério da Saúde, 2008).

Estas diretrizes se atualizam através de dispositivos, entendidos como 'tecnologias leves', que expressam modos de fazer instituintes ao dispararem mudanças nos modelos de atenção e de gestão. Dentre esses dispositivos, em permanente processo de criação e recriação, destacam-se: o Colegiado Gestor; o Grupo de Trabalho de Humanização (GTH), Câmara Técnica de Humanização (CTH) e Coletivos Ampliados da PNH; Contrato de Gestão; Sistemas de escuta qualificada para usuários e trabalhadores, como ouvidorias, grupos focais, dentre outros; Visita Aberta e Direito à Acompanhante; Programa de Formação em Saúde e Trabalho (PFST) e Comunidade Ampliada de Pesquisa
(CAP); Equipe Transdisciplinar de Referência e de Apoio Matricial, Projeto Terapêutico Singular e Projeto de Saúde Coletiva; Projetos Cogeridos de Ambiência, Acolhimento com Classificação de Risco (ACCR); dentre outros (Ministério da Saúde, 2008).

Vale lembrar que a humanização apareceu como plataforma política de saúde na $11^{\mathrm{a}}$ Conferência Nacional de Saúde, realizada em 2000, conforme a temática da Conferência - Efetivando o SUS: Acesso, Qualidade e Humanização na Atenção à Saúde, com controle social. (Ministério da Saúde, relatório final, 2001).

A formulação da PNH como política transversal do SUS, e não mais limitada a programas voltados para áreas ou serviços específicos, como a 'Humanização do Parto', o 'Programa Nacional de Humanização da Assistência Hospitalar' (PNHAH), dentre outros, ampliou e aprofundou, diríamos, o conceito de humanização nas práticas de saúde no SUS.

Ressaltamos discussões desenvolvidas por Benevides \& Passos (2006), ao proporem a seguinte questão:

\footnotetext{
(...) qual o sentido de uma política de humanização que não se confunda com
} 
um princípio do SUS, o que a tornaria ampla e genérica, nem abstrata porque fora das singularidades da experiência, nem que aceite a compartimentalização, mas que se afirme como política comum e concreta nas práticas de saúde? (Benevides \& Passos, 2006, p. 38).

Importante marcar estas características da PNH como uma política que se constrói a partir das experiências concretas de sujeitos/agentes envolvidos com as práticas de saúde nos múltiplos espaços de trabalho do SUS, uma política que procura disparar movimentos de mudança na atenção e gestão do processo de trabalho em saúde (Trajano, 2012).

Em oposição à idealização do humano, este é tomado aqui no sentido da existência concreta de sujeitos singulares, implicados com processos de mudanças e criação de novas realidades. A Humanização como 'conceito-experiência', não como um 'novo modismo', numa abordagem fragmentada e padronizada, o que levaria a práticas que se caracterizariam como 'sintomáticas', no sentido de padronização das ações e repetição de modos de funcionar, conforme discussões disparadas por Benevides e Passos (2006):

$$
\begin{aligned}
& \text { Se partimos da crítica ao conceito- } \\
& \text { sintoma, concluímos afirmando a } \\
& \text { humanização como um conceito- } \\
& \text { experiência que, ao mesmo tempo, } \\
& \text { descreve, intervém e produz a realidade } \\
& \text { nos convocando para mantermos vivo } \\
& \text { o movimento a partir do qual o SUS se } \\
& \text { consolida como política pública, } \\
& \text { política de todos, política para qualquer } \\
& \text { um, política comum (op. cit., p. } 39 \text { ). }
\end{aligned}
$$

Esse debate sobre humanização da saúde como um 'conceitoexperiência' disparou produções de textos e posicionamentos por diferentes autores implicados com a construção do SUS. Dentre eles ressaltamos o artigo produzido por Campos (2006), em que relaciona a humanização aos conceitos de Defesa da Vida e de Paidéia, e, ao final conclui que a humanização "é um conceito que tem um potencial para se opor à tendência cada vez mais competitiva e violenta da organização social contemporânea" (op. cit., p. 45). Nessas discussões, diríamos, introduz a temática da violência social que afeta o cotidiano de trabalho em saúde, quando aborda a humanização como 'um alerta contra a violência' (Campos, 2006): “a humanização tende a lembrar que 
necessitamos de solidariedade e de apoio social. É uma lembrança permanente sobre a vulnerabilidade nossa e dos outros. Um alerta contra a violência” (op.cit., p 45).

Por tudo isto, propomos este debate sobre a Política de Humanização e a Reforma Psiquiátrica, em especial, a Política de Saúde Mental de Belo Horizonte - um encontro entre movimentos de luta que transformam relações entre sujeitos e criam novas realidades de trabalho no SUS.

Agraciada em 2004, pelo Ministério da Saúde, com o Prêmio HumanizaSUS Davi Capistrano Filho, a Política de Saúde Mental de Belo Horizonte destacou-se do conjunto dos trabalhos premiados por ser entre tantos - centenas de exitosas práticas de Humanização do SUS aquela que inscrevia a experiência de desconstrução do manicômio no contexto da construção do SUS. A saúde mental evidencia o ponto de radicalidade a que uma política de saúde pode chegar, quando assume, no cuidado, a busca da autonomia e do exercício do protagonismo dos sujeitos. Assim, desvela a humanidade presente na relação intersubjetiva que envolve todo processo de saúde. Dito de outra maneira: a radicalidade da humanização passa pelo reconhecimento e aceitação do outro como alteridade e sujeito dotado de direitos. Humanizar, nesta concepção, é mais que trato delicado, digno e respeitoso, implica uma prática clínica comprometida com a invenção de humanidades: algo que a saúde mental conhece de perto na prática efetiva de desconstrução de muros. Nesta perspectiva, a partir do princípio referente à inseparabilidade entre clínica e política, entre produção de saúde e produção de sujeitos, encontram-se PNH e luta antimanicomial.

Este prêmio nos trouxe uma dupla alegria: a da premiação em si e a da nomeação. Davi Capistrano Filho, soldado da guerra contra todas as formas de miséria e audaz construtor da utopia do direito à saúde, inventor de mundos antes inexistentes e talvez impossíveis de passar à realidade efetiva sem a presença de sua força e coragem, tornou mais valioso $\mathrm{o}$ destaque, e também mais exigente. É preciso manter-se à altura do nome recebido para continuar a merecê-lo. É preciso não desistir, como insistia Davi, de tomar o céu de assalto, mesmo quando todos afirmem o oposto e o coro do consenso aponte a resignação à 
realidade injusta como única saída, tornando mais amplo o campo das possibilidades e das realidades, sendo as últimas efeitos da ousadia desobediente e propiciadora de mundos novos.

$\mathrm{Na}$ saúde mental lutamos contra muros visíveis e invisíveis, contra modos sutis e violentos de cerceamento da liberdade do homem louco, obstáculos que impedem estes sujeitos de existirem em sua singularidade e de pertencerem ao mundo civilizado e cidadão. A institucionalização da loucura expressa um dos mais completos e sólidos processos de desumanização, pois articula dois modos distintos e complementares de violência: à segregação dos corpos se articula e duplica o processo de exclusão e anulação da subjetividade. Ensina-nos Foucault (1987) que a condenação à cidadela do bem, o manicômio, se fez acompanhar do processo de destituição da verdade na experiência da loucura. Alijada do lugar de saber, esvaziada do sentido de verdade, a loucura torna-se para a razão mero objeto de um saber. Tal condição autorizará as muitas violências que as páginas da história registram, desde a humilhante condição de restos sociais condenados ao tratamento indigno, excludente e mortífero, muitas vezes, até as formas mais sutis de violação, como a interdição civil colocada como recurso necessário à vida de um sujeito em sofrimento mental. É como se a experiência da vida, na loucura, apenas fosse possível com a destituição do sujeito de direitos, fazendo deste um sujeito amputado e subtraído da responsabilidade que anima e delimita a liberdade como exercício de aprendizado do viver.

Por isso, a humanização na saúde mental ganha um sentido mais ampliado. Aqui, é preciso ir além da abolição das práticas que violam direitos, desrespeitam a cidadania; fazse necessário ir ao ponto de raiz da humanização: o reconhecimento do outro como ser igual a mim - em direitos, e radicalmente distinto, em sua subjetividade. Quando a saúde se humaniza ela descobre, ou melhor, redescobre algo que não devia ter esquecido: nossa prática é a arte humana de buscar alívio para a dor, e como arte que é, é também instrumento de invenção de novos modos de existir. 


\section{A desconstrução dos muros: vinte anos de história}

Até 1993, Belo Horizonte relacionava-se com a loucura que a habita tendo o manicômio como único mediador. Não havia, até aquele momento, nada do que integra o cenário das práticas substitutivas. Não havia outra marca, nem outra referência cultural além da secularmente estabelecida. Gradualmente, e por sucessivos gestos de decisão, outra arquitetura, novos lugares e modos de cuidar ganharam materialidade $\mathrm{e}$ introduziram na cena urbana imagens que até então pertenciam ao campo das utopias.

Distintos pontos de referência da loucura se multiplicam e respondem por nomes antes desconhecidos entre nós. Centros de Referência em Saúde Mental (CERSAM), Centros de Convivência, Equipes de Saúde Mental em Centros de Saúde, Serviços Residenciais Terapêuticos, Equipes de Saúde da Família, SAMU, Serviço de Urgência Psiquiátrica Noturno, Incubadora de Empreendimentos Econômicos Solidários, Consultórios de Rua, Equipes Complementares de Atenção à Saúde Mental da Criança e do
Adolescente, Arte da Saúde, todos inexistentes até 1993, realidade em 2012, são singulares estações de cuidado e invenção de vida que compõem a rede substitutiva. Uma realidade potente e vigorosa, que exige ampliação e fortalecimento para continuar a tecer a cidadania com fios singulares e vivos.

A transformação operada neste intervalo não alcançou ainda sua meta: a substituição de todos os hospitais psiquiátricos, primeira etapa do processo de desconstrução da lógica manicomial. Neste período, a construção da rede substitutiva deslocou o eixo da questão, diminuiu acentuadamente o número de leitos psiquiátricos e a presença do manicômio na vida, nos corpos dos sujeitos e no desenho da política e precisa manter-se nesta direção para, enfim, e num futuro próximo, substituílo integralmente, como é seu compromisso.

Em cada um dos serviços citados acima uma nova prática 'desistitucionalizadora' se produz em confronto com a tradição. Outro modo de cuidar e como consequência deste, inventam-se, criam-se, a cada instante, outras formas, e estratégias singulares 
para fazer margem ao sofrimento psíquico, mas também para alterar a percepção e os significados atribuídos pela sociedade a esta experiência. No permanente e, às vezes, tenso diálogo entre razão e loucura, os dois polos são convidados a encontrar o ponto de acordo e convívio. À razão é pedido, de início, que abra mão de suas certezas para reconhecer a lucidez presente na lógica de pensamento avessa a sua, e à loucura que não se feche em sua verdade, que abra espaços para a troca e o convívio. A Luta Antimanicomial desfaz o nexo que inventou e legitimou o manicômio: a desumanização da loucura, e convida ao reconhecimento da cidadania e da humanidade como condições estruturantes de um tratamento. Nesta outra lógica de abordagem da loucura, clínica e política se misturam produzindo novas subjetividades, novas relações entre os sujeitos que se encontram no cuidado em saúde mental.

Uma mesma diretriz ética orienta e conecta todos os pontos da rede. Para cada estação de cuidado vale a premissa de fazer caber no universal da cidadania o singular de toda diferença. Este princípio está colocado e orienta o trabalho em todos os momentos de encontro dos sujeitos com os serviços e suas equipes. Na crise ou fora dela o trabalho deve orientar-se para ajudar os sujeitos a se manterem na vida, tratando seu sofrimento sem excluir seu corpo do convívio e acima de tudo, sem autorizar-se a suprimir os seus direitos de cidadão. Fazer caber a diferença implica em dar suporte para a invenção do pertencimento, o oposto da adequação ao lugar prévio e normatizado destinado à produção de iguais.

Destacaremos o colorido próprio dado pela saúde mental à Política de Humanização, ou como esta é matizada no fazer da clínica antimanicomial. Escolhemos algumas perspectivas para ilustrar a compreensão e os efeitos da política de humanização no interior da prática dos serviços substitutivos: a valorização da palavra do louco, a produção artística/cultural, expressão criativa e criadora de outra inscrição da experiência da loucura, o retorno do exílio manicomial e a consequente (re)aprendizagem de tornar-se habitante de uma cidade, a inserção dos sujeitos nos dispositivos de cuidado não especializados, particularmente, na atenção básica e, por fim, a expressão 
da palavra do cidadão, através da atuação do movimento social.

\author{
"Hora da palavra. Quando não se diz \\ nada. \\ Fora da palavra, quando o mais dentro \\ aflora" \\ (Caetano Veloso)
}

A porta aberta de um CERSAM, endereço privilegiado e estratégico na rede para o cuidado à crise, dá acesso a um cuidado radicalmente distinto do tratamento classicamente ofertado à dor intensa que afeta a alma, perturba os laços e por vezes coloca em risco os sujeitos, suas vidas, suas relações. Contornar pela palavra e não pela grade ou muro o sofrimento que se manifesta, cria possibilidades e impõe responsabilidades e compromissos e é isto o que busca a rede, em cada uma de suas estações, na acolhida a cada usuário, a cada situação que se apresenta. Buscar na palavra a via para esvaziar o sentido que atormenta e traz riscos, ressignificando o conflito que se instalou de repente ou redescobrindo no encontro com outra palavra, uma margem para o descanso. Palavras pronunciadas por corpos que se fazem endereço e suporte, habitantes de lugares que protegem e guardam múltiplos dizeres sobre o humano no homem, sobre o desvario e a regra, a criação e a rotina, sempre dosados pela medida singular do desejo e das capacidades que compõem as histórias individuais e coletivas.

A primeira borda oferecida por um CERSAM vem da palavra, do acolhimento ao estranho e sua língua estrangeira e será o dizer de cada sujeito a bússola a indicar o norte do cuidado, a saída do sofrimento ou o retorno, ao contorno da subjetividade, do conflito que não encontrou sentido, trouxe perplexidade e desfez o arranjo que sustentava o curso do viver.

A um CERSAM é possível chegar conduzido pela orientação da decisão pessoal, pelo querer próprio ou pelas mãos e apoio de outros, a família, os amigos, os serviços da rede de urgência, o SAMU ou pela polícia. E importa saber que é possível chegar, ser acolhido e tratado, sem a interposição de nenhum mecanismo burocrático.

Criado, estrategicamente, para substituir o hospital psiquiátrico e sua resposta padrão, este dispositivo desconstrói ainda a tradução da crise oferecida pela lógica manicomial. Todos os recursos postos à disposição do sujeito operam buscando articular os 
laços e redes como modo de tratar o sofrimento, oferecendo acolhida nas margens da palavra e no trato delicado.

A singularização do tratamento, princípio do trabalho num serviço como este, desfaz a clássica padronização que anula e amplia a dor, ao não reconhecêla tão múltipla quanto são os humanos, e inova - humanizando o tratamento, ao inverter a resposta totalitária da internação, muitas vezes imposta aos sujeitos, pelo convite e consentimento ao tratamento.

Reconhecer o tratamento como um direito conduz a reconhecer, na mesma medida, que direito não se impõe. Cabe a cada um decidir quando e como gozará do bem que lhe oferta a cidadania. Fato que torna mais complexa a tarefa do cuidado e impõe a necessidade de um deslocamento: é preciso abandonar a posição autoritária para passar a investir na construção da parceria e do convencimento possível e respeitoso. Sustentar o convite ao tratamento torna mais complexa, exigente e rigorosa a tarefa, mas também, a faz inventiva.

O cotidiano destas experiências é feito de relatos inusitados, de curiosas cenas de soluções ou saídas não previstas em nenhum manual técnico- científico. Nestas cenas destaca-se, sobretudo, a solidariedade como elemento fundamental na invenção de outros modos de habitar o corpo e a cidade, contornando, pela palavra, o sofrimento que transbordou e definindo, nas margens desta, as fronteiras da cidadania.

\footnotetext{
"E se de repente a gente não sentisse a dor que a gente sente e finge.

Se de repente a gente distraísse o ferro do suplício, ao som de uma canção"

(Chico Buarque)
}

Ao introduzir a arte e a cultura no conjunto dos dispositivos de substituição do manicômio escolhemos fazer mais que o estritamente necessário. Em outras palavras: entendemos que o necessário, para cada sujeito, nem sempre se eqüivale ao útil e tampouco precisa ser restrito. O necessário, para cada um, pode articular-se ao desejo e ter haver com algum tipo de inquietação, com os sonhos que nos habitam e que só se satisfazem quando ganham formas, sons, letras ou gestos e nos levam para além de nós mesmos, endereçando ao outro, parte de nosso universo particular ou de nossa visada do mundo. 
A arte se insere, no projeto de desconstrução do manicômio, como um recurso a mais do qual os sujeitos podem lançar mão para se conectarem, para conviverem prazerosamente com seus semelhantes, podendo assim, transitar pela cidade não mais como um doente, ou ainda pior, como pura representação da doença, mas como alguém capaz de estabelecer trocas e deste modo dar testemunho dos inúmeros efeitos de tratamento do insuportável que o laço social favorece, seja pela via da arte, enquanto produção artística, seja pelo simples fato de ver-se incluído na família, ou por ter amigos.

Superado o obstáculo imposto pela razão de afastar-se da vida para tratar a dor, abre-se a possibilidade para a colocação de novas indagações. A reinvenção dos laços ou a tessitura fina e delicada destes, ganha cores e vida quando sacia sua sede na fonte da cultura.

Temos aprendido e ensinado, na prática dos Centros de Convivência e no Arte da Saúde, em especial, que a arte é alento poderoso no trato da dor, mas é acima de tudo, ferramenta potente na invenção de humanidades. O encontro da arte com a loucura, no trabalho fino e delicado das oficinas e projetos, propicia trocas criativas, lúdicas, e gera obras de qualidade estética incontestável que testemunham o valor da aposta na liberdade e seus efeitos humanizantes e revolucionários.

Produzindo pensamento e beleza os participantes desta experiência vivenciam outras possibilidades de trato do sofrimento, encontrando na música, na arte, na poesia, a suspensão do martelo do martírio, a distração ou o intervalo preciso que dá lugar ao trabalho do pensamento, à subjetivação da dor vivida e sua transmutação em música, em arte cênica ou plástica; enfim, em reinvenção de si. Um fecundo trabalho e um rigoroso testemunho da humanização, em sua dimensão primeira: a atribuição de sentido e representação ao mundo habitado, ou seja, a invenção do mundo dos humanos, espaço construído pelo movimento das mãos e pelo trabalho dos sonhos e do pensamento. Dimensões que nos distinguem, no reino animal, de todos os demais viventes.

\footnotetext{
"Onde pode habitar-se um fraco humano, onde terá segura a curta vida?" (Camões)
} 
São conhecidas e ainda tristemente reais e cotidianas, em hospitais psiquiátricos brasileiros, as cenas de abandono. Moradores de lugares destituídos de dignidade, um número expressivo de sujeitos enclausurados em manicômios esperam pelo dia do fim deste cativeiro. Alguns, não chegarão a transpor este obstáculo e morrerão esquecidos. Esta condição revela a proximidade existente entre as instituições totais e os campos de concentração. Todos, sem exceção, são espaços de absoluta desumanização, de redução do outro à condição de objeto de um saber, de um discurso, de uma política; vidas violentadas e mortificadas que quando têm a chance de regressar à cidade necessitarão de suportes sutis e decididos para readquirir o que de mais precioso se perdeu: a filiação a um território e a proteção ofertada pelas redes solidárias de pertencimento.

Após anos e décadas de exílio, no retorno à condição de habitante livre de uma cidade, os sujeitos experimentam e redescobrem o valor das pequenas e banais ações cotidianas nas quais tecemos nossa biografia. Ir à padaria, escolher o alimento predileto, decidir a hora do descanso e do lazer, ter agenda de compromissos, festa de aniversário, escolher as próprias roupas e responder, em conjunto, pela organização da casa, são decisões corriqueiras, absolutamente triviais e que fazem toda a diferença e descontroem, em ato, o pesado processo de desabilitação que se abateu sobre os corpos e vidas, em nome de um tratamento.

A desconstrução da mais dura segregação manicomial conduziu a Reforma Psiquiátrica ao delicado aprendizado do ofício do joão-de-barro: aprendemos a construir moradias, passamos à invenção e montagem de casas para fazer caber a diferença, resgatando o direito outrora suprimido, mas, preservando neste espaço o sentido e a função atribuídos a qualquer casa: ser lugar para a habitação do humano, para inscrição das marcas singulares e para acolhida dos sonhos, angústias e alegrias que qualquer teto abriga. Cada serviço residencial terapêutico é, a um só tempo, reapropriação do direito à cidade e de (re)descoberta da humanidade esquecida. 
"Uma vida que é vivida

E outra vida que é pensada,

E a única vida que temos

É essa que é dividida”.

(Fernando Pessoa)

A tessitura da rede, fio sobre o qual transitam os sujeitos e suas histórias de vida, encontra no cuidado longitudinal desenvolvido na atenção primária em saúde, localização e compromisso que ampliam e fortalecem a clínica antimanicomial. A potência do encontro entre profissionais e serviços não especializados e os sujeitos com sofrimento psíquico ou mental resgata para as diferentes equipes de saúde e para os usuários, a oportunidade de um fazer clínico rigoroso e delicado, sustentado pelo compromisso com a defesa da vida.

$\mathrm{Na}$ atenção básica em saúde o cuidado deve ser construído sobre o solo de um território conhecido e habitado e elabora histórias no aprendizado extraído dos encontros entre unidades, equipes de saúde e usuários. Em parceria com a Saúde Mental, a Saúde da Família, estratégia adotada pelo Sistema Único de Saúde para fortalecer os laços entre a porta de entrada no sistema e os usuários, empresta seu saber, suas tecnologias de cuidado e sua vinculação com o território para fazer mais viva a rede de desconstrução do manicômio, dando a este projeto político o toque preciso do fazer clínico que devolve à loucura $\mathrm{o}$ direito ao corpo.

Tomando posição, a exemplo dos especialistas, as Equipes de Saúde da Família não recuam diante da loucura e fazem mais: introduzem, para os usuários e para a rede, a medida do cuidado, de fato, humanizado. $\mathrm{O}$ cuidado que atravessa a barreira do saber técnico, que não se deixa inibir pelo mesmo e por isso não recua, contribui para localizar o sofrimento como um dado e não mais totalidade de uma biografia. Circulando entre crianças que chiam, se inquietam ou paralisam, adolescentes que interrogam e contrapõem a autoridade com a audácia de uma descoberta, mulheres e suas dores, idosos e suas fragilidades, sujeitos com sofrimento mental jovens, adultos ou idosos, encontram na atenção básica inscrição e cuidado para seus corpos e vidas, tanto a que sentem na pele quanto a que projetam no pensamento.

É preciso ainda destacar no cuidado ofertado pela rede básica a contribuição dos Agentes Comunitários 
de Saúde, trabalhadores cujo saber não provêm da técnica nem da ciência, mas do território e da experiência. São estes parceiros que nos informam sobre os modos como os sujeitos com sofrimento psíquico vivenciam o território, se são incluídos ou rechaçados pelas redes existentes no mesmo, se aí encontram apoio e solidariedade ou se, ao contrário, vivenciam o abandono e a solidão. Este conhecimento é o diferencial que ilumina e, muitas vezes, aponta a saída possível para os casos. E lembramos aqui a ergologia francesa (Schwartz \& Durrive, 2007; Trajano, 2012) ao conceituar trabalho como atividade humana, um lugar em que a vida se manifesta, em que encontramos a 'presença viva de uma pessoa', com sua história, seus saberes, seus valores, suas experiências. Nesta perspectiva, diferentes saberes se articulam na realização do trabalho: saberes disciplinares ou técnico-científicos e saberes 'da experiência' ou gerados na própria atividade.

"E transformando o mundo e a
humanidade,
transformai-vos. Saibam abandonar a si
mesmos!"
(Bertold Brecht)

O constante e fecundo diálogo com o movimento social da luta antimanicomial é, sem dúvida alguma, um dos traços singulares da Política de Saúde Mental de Belo Horizonte. A construção e sustentação da rede, mesmo em momentos de mudança na gestão municipal, é efeito da atuação e intervenção dos movimentos sociais no cenário político. É importante destacar que a criação destes espaços de exercício da força política dos atores que fazem a Reforma Psiquiátrica usuários, trabalhadores, familiares, como coletivos cidadãos, engajados e comprometidos com a consolidação desta política é tanto efeito quanto uma necessidade.

A luta antimanicomial, ao romper com a tutela do saber técnico especializado, inseriu na agenda das cidades o debate sobre o lugar social da loucura, ou seja, colocou esta questão na dimensão de problema da democracia e não mais uma questão restrita a especialistas e a profissões. Como pauta política, compete aos cidadãos sua condução e seu futuro.

A riqueza produzida nestes coletivos, que insistimos: são constituídos por cidadãos vindos de lugares distintos e despidos de insígnias 
ou etiquetas, e comprometidos com a cidadania própria e a do outro, revelase na construção da rede, sempre mais criativa e coerente quando afinada com o pensamento e as propostas formuladas em conjunto com estes atores.

As saídas para os impasses e obstáculos que se apresentam, quando construídas coletivamente são mais pontentes, pois já nascem da ação pública e têm como destino tornarem-se patrimônio coletivo, apropriado e defendido por muitos e, em especial, por seus beneficários diretos: os usuários e suas famílias.

"Se lembra do futuro que a gente combinou"

(Chico Buarque)

Revolucionando a prática de abordagem da loucura, a Reforma Psiquiátrica humanizou e transformou a clínica e o processo de trabalho voltado para o cuidado deste usuário, reinscreveu o sofrimento dando-lhe justa significação: uma contingência na experiência humana. Reformulada a questão foi possível abrir portas, dispensar grades, recusar a indústria da loucura e sua produção de mortes e dor, para fazer surgir rostos e histórias de vida, necessidades a atender e direitos a conquistar, e indo muito além dos remédios e das terapias, descobrir o encanto na banalidade cotidiana e a surpresa do ato de criação poética, musical, plástica ou as palavras e os mundos escritos com linha e agulha.

As estórias ou os casos clínicos da saúde mental, registrados no interior dos serviços da rede, são sempre crônicas sensíveis que revelam um labor essencialmente humano, criativo e corajoso e que por isto transmitem o melhor de um ensino em saúde. Não por acaso, algumas experiências de Reforma Psiquiátrica passam, agora, a acolher os novos profissionais em residências profissionais que buscam formar, transmitindo o saber que se constrói na prática.

Mas, eis que no meio deste percurso, medos e dúvidas antes endereçados aos sujeitos com sofrimento mental, se recolocam como uma interpelação ameaçadora à Reforma Psiquiátrica, a partir das necessidades dos usuários de álcool e outras drogas.

O conjunto denominado "outras drogas" inclui uma a qual se atribui o poder de perturbação da paz e do sono sociais: o crack. Mesmo que dados epidemiológicos demonstrem não haver 
magnitude no consumo capaz de justificar tão imenso temor, ainda assim, insiste a ordem pública e seu porta-voz, a mídia, no fraseado alarmista que legitima a violência e o arbítrio. Diante disto, não há como não colocar a dúvida: restará ainda, passado o horror - que não sabemos quanto tempo durará - preservado um mínimo de cidadania no cuidado com os que equivocam na vida? Restará, para a saúde, trato humano e humanizado?

A Luta Antimanicomial e a Reforma Psiquiátrica não recuaram e aceitaram o desafio de propor lugar na saúde para inscrição da drogadição, decisão que as colocou no centro como um alvo a ser abatido, de um debate confuso, ameaçador e superficial sobre o problema.

As complexas ramificações desta questão têm sido reduzidas à dimensão do consumo, posição que encobre ou ignora o óbvio: não existe consumidor sem vendedor, nem oferta sem demanda. Esta é a lógica do mercado! Contudo, as políticas públicas sobre drogas atualmente ocupam-se, de forma maciça, em tratar, reintroduzindo no campo terapêutico a violência e o autoritarismo como medida de cuidado.
Traços de uma prática que a rede substitutiva se esforça para superar.

$\mathrm{O}$ poder de sequestro retorna e junto com este os lugares de segregação. E, o que é pior, retornam numa tentativa de composição impossível, ou seja, retornam como recursos e dispositivos de uma rede que se inventou para superá-los. O convite e o consentimento ao tratamento foram a primeira prova pela qual passou $\mathrm{o}$ cuidado em liberdade. E é preciso lembrar que a travessia foi exitosa, o que nos autoriza a propor e sustentar que a liberdade é terapêutica também na abordagem desta questão.

Loucura e drogadição são experiências eminentemente humanas. E, a luta antimanicomial demonstrou que a humanização é a melhor medida de cuidado, pois recoloca no sujeito e em sua subjetividade aquilo que interroga e questiona a razão e sua lógica. A loucura - tanto aquela expressa pela estrutura psicótica quanto a adição às drogas, não retira dos sujeitos sua humanidade, nem pode subtraí-los de sua cidadania. Esta foi a primeira tomada de posição, primeiro corte estabelecido pela luta antimanicomial com a tradição, gesto que permitiu a desmontagem das 
práticas autoritárias, violentas e coercitivas e inaugurou o campo de possibilidades para invenção de uma política efetivamente comprometida com o sofrimento humano e com a defesa da vida.

E, ainda que este processo histórico não tenha se consolidado e transformado por completo a percepção social sobre a experiência da loucura, já não se pode falar da mesma ignorando as transformações que a ousadia antimanicomial produziu. Das leis à prática, uma real transformação se operou e desnudou a crueldade da lógica manicomial e os efeitos de produção de vida do projeto que a subverte.

Sabemos que o diabo não há, que 'o que há é homem humano'. E, o que é do humano não nos é estranho! Por isso, apostamos na liberdade, que é o avesso da dependência, como remédio e direito para os que enlouquecem pela via da adição.

No início de nosso percurso as questões que tentavam impedir a implantação da prática antimanicomial não diferiam das que ora se formulam: $o$ horror à loucura é semelhante ao horror ao crack, como se assemelha a afirmativa da incapacidade do sujeito para reconhecer a necessidade de ajuda, fato que justifica o recurso da internação involuntária. O que há de novo, além do deslocamento, do giro da questão agora endereçada ao corpo e vida dos que usam e abusam das drogas? A triste novidade talvez seja não o crack e seus efeitos, mas os usos que dele tem sido feitos na política e na vida pública e que podem interromper, em nome da ameaça imaginária, o curso e o futuro das políticas públicas e da própria democracia.

\section{Notas}

${ }^{1}$ Texto inédito, não oferece conflito de interesses.

${ }^{2}$ Buscamos aqui os sentidos construídos pelo 'institucionalismo', sistematizados por Baremblitt (1992), ao retomar a concepção da 'vida social como uma rede' - em que os processos são imanentes um ao outro (no sentido de imanências - a coextensão, um dentro do outro, incluindo no outro), distingue o 'molar/macro', lugar da ordem, das entidades claras, dos limites precisos, da estabilidade, da conservação, do instituído; daquilo que é 'molecular/micro', tanto no sentido da física, da química, da biologia, quanto 
no 'sentido social e desejante', lugar da produção/criação/invenção, 'eclosão

\section{Referências}

Baremblitt, G. (1992). Compêndio de Análise Institucional e outras correntes: teoria e prática. Rio de Janeiro: Rosa dos Tempos.

Benevides, R. \& Passos, E. (2006). Humanização na Saúde: um novo modismo? Revista Interface Comunicação, Saúde, Educação, São Paulo, 9 (17), 389-406.

Campos, G. W. de S. (2005). Humanização na Saúde: um projeto em defesa da vida? Revista Interface - Comunicação, Saúde, Educação, São Paulo, 9 (17), 398-403.

Ministério da Saúde do Brasil. (2001). $11^{a}$ Conferência Nacional de Saúde. Efetivando o SUS: Acesso, Qualidade e Humanização na Atenção à Saúde, com controle social. Relatório Final. Brasília: Ministério da Saúde.

Ministério da Saúde do Brasil. (2008). Política Nacional de Humanização (PNH): humanizasus. Documento Base.
(4 ed.). Brasília: Ministério da Saúde.

Foucault, M. (1987) História da Loucura na Idade Clássica. São Paulo: Ed. Perspectiva.

Secretaria Municipal de Saúde de Belo Horizonte. (2008). Política de Saúde Mental de Belo Horizonte: o cotidiano de uma utopia. Belo Horizonte: Secretaria Municipal de Saúde.

Schwartz, Y. \& Durrive, L. (2007). Trabalho e Ergologia: conversas sobre a atividade humana. (J. Brito \& M. Athayde, Trads.). Rio de Janeiro: EDUFF.

Trajano, A. R. C. (2012). O Trabalho no SAMU e a Humanização do SUS: saberes-atividade-valores. Tese de Doutorado. Programa de PósGraduação em Conhecimento e Inclusão Social, Universidade Federal de Minas Gerais, Belo Horizonte.

$\overline{\text { Ana Rita Castro Trajano - Consultora }}$ do Ministério da Saúde / Política Nacional de Humanização; Pesquisadora do Núcleo de Estudos sobre Trabalho Humano (NESTH) / Universidade Federal de Minas Gerais (UFMG); Professora em Curso de Especialização em Política Pública da 
UFMG / Departamento de Ciência

Política; Graduação e Mestrado em

Psicologia / UFMG; Doutora em

Educação / UFMG.

E-mail: aritatrajano@yahoo.com.br

Rosemeire Silva - ex-coordenadora de Saúde Mental de Belo Horizonte; militante do Fórum Mineiro de Saúde Mental; membro da Comissão Nacional de Direitos Humanos do Conselho Federal de Psicologia; Conselheira Nacional de Saúde (triênio 2012/2014); Psicóloga.

E-mail: silva-rosemeire2004@ig.com.br 